\title{
Research on the ability of propionic acid and vitamin B12 biosynthesis by Propionibacterium freudenreichii strain $\mathrm{T} 82$
}

\author{
Kamil Piwowarek • Edyta Lipińska • Elżbieta Hać-Szymańczuk • \\ Anna Bzducha-Wróbel · Alicja Synowiec
}

Received: 31 July 2017 / Accepted: 20 November 2017/Published online: 25 November 2017

(C) The Author(s) 2017. This article is an open access publication

\begin{abstract}
The purpose of this study was to determine the potential for biosynthesis of propionic acid and vitamin B12 by Propionibacterium freudenreichii T82 in a medium containing various sources of carbon (glucose, fructose, and saccharose). These sugars are present in apple pomaces, which are the waste from the production of apple juice. Using statistical analysis design of experiments (DoE), the results allowed us to determine which sugars (carbon sources) exert the most beneficial influence on the biosynthesis of propionic acid and cobalamin. The highest production of propionic acid by the tested bacterial strain was obtained in a medium in which glucose accounted for at least $50 \%$ of the available carbon sources. Depending on the culture medium, the concentration of this metabolite ranged from 23 to $40 \mathrm{~g} / \mathrm{L}$. P. freudenreichii T82 produced the smallest amount of acid in medium in which the dominant nutrient source was saccharose. The results obtained indicated an inverse relationship between the amount of acid produced by the bacteria and vitamin B12 biosynthesis. Because of the high efficiency of propionic acid biosynthesis by $P$. freudenreichii $\mathrm{T} 82$, the prospect of using this strain
\end{abstract}

K. Piwowarek ( $₫)$ · E. Lipińska · E. Hać-Szymańczuk ·

A. Bzducha-Wróbel · A. Synowiec

Department of Biotechnology, Microbiology and Food

Evaluation, Division of Food Biotechnology and

Microbiology, Faculty of Food Sciences, Warsaw

University of Life Sciences - SGGW (WULS-SGGW),

Nowoursynowska 159c Street, 02-776 Warsaw, Poland

e-mail: kamil_piwowarek@sggw.pl to obtain propionate with the simultaneous disposal of waste materials (such as apple pomaces) which contain glucose and/or fructose is very promising.

Keywords Propionic acid · Acetic acid · Vitamin B12 Propionibacterium $\cdot$ Carbon sources $\cdot$ DoE

\section{Introduction}

Bacteria of genus Propionibacterium have been traditionally divided into two groups: skin (acnes) and classic (dairy). Classical strains include, among others, the species Propionibacterium acidipropionici, Propionibacterium jensenii, Propionibacterium thoenii and Propionibacterium freudenreichii (ssp. shermanii, ssp. freudenreichii) (Meile et al. 1999), of which the first three have recently been reclassified as members of the genus Acidipropionibacterium (Scholz and Kilian 2016). Classical Propionibacterium are a source of useful metabolites such as propionic acid and vitamin B12 (Meile et al. 1999; Patrick and McDowell 2015).

Propionic acid is used to inhibit the growth of yeast and molds in prepacked sliced bread, rye bread, breads with reduced calories, and partially baked rolls, pita bread, pastry products and animal feed. Propionic acid also is an essential indirect component in production process of the cellulose fibers, herbicides, perfumes, and pharmaceuticals (Suomalainen and Mäyrä- 
Makinen 1999, Gwiazdowski and Gwiazdowska 2008). Propionic acid for industrial purposes is currently synthesised only in chemical processes, as this is still more economical than microbial processes using propionic acid bacteria. However, due to the serious environmental damage that can be caused by chemical production of propionic acid, as well as due to the rise in demand for natural and ecological food products, there is an increasing demand for the microbial production of propionic acid, along with the desirability of using waste materials. This should reduce the cost of natural production of propionc acid and make it profitable and should have environmental benefits (Baumann and Westermann 2016). Such waste materials could include apple pomaces, which contain sugars (glucose, fructose, saccharose), proteins, pectins, fiber, vitamins and organic acids, which may affect the efficiency of synthesis of propionic acid or cobalamin by Propionibacterium spp. and relatives.

Bacteria of the genus Propionibacterium and relatives seem the most appropriate for the biotechnological production of propionic acid. Due to their wide variety of enzymatic systems, they can use carbon from various sources, for example: glucose (Himmi et al. 2000), xylose (Carrondo et al. 1988), lactose (Hsu and Yang 1991), saccharose (QuesadaChanto et al. 1994), lactic acid (Barbirato et al. 1997), maltose (Zhu et al. 2012) and whey (Lewis and Yang 1992). These bacteria can be used in the reprocessing of waste materials including glycerol (Yazdani and Gonzales 2007; Zhu et al. 2010), hemicellulose hydrolysates (Ramsay et al. 1998), corn flour (Huang et al. 2002) and cane molasses (Feng et al. 2011).

The most favourable bacteria for industrial production of vitamin B12-due to their Generally Recognized as Safe status (GRAS) and ability to synthesise active forms of this metabolite-may be strains of $P$. freudenreichii. However, currently commercially produced cobalamin uses a genetically modified strain of Pseudomonas denitrificans (without GRAS status) (Blanche et al. 1989; Miyano et al. 2000; Roman et al. 2001). Because in many parts of the world the use of genetically modified organisms (GMOs) still causes controversies, the search for appropriate carbon source and microbes capable of producing this metabolite with high efficiency, without interfering with their genomes, remains a challenge.

In these studies we used the mixture design method of DoE (Design of Experiments) as a tool to facilitate optimising composition of carbon sources in the culture medium of $P$. freudenreichii (Mason et al. 1989). The statistical method of DoE provides an efficient plan for experimentation, so that many factors influencing a process can be simultaneously studied. Statistical approaches have become useful tools for understanding the interactions among various parameters with a minimum number of experiments (Gupta et al. 2007). The DoE method has many benefits in comparison to conventional one-factor-at-a-time methods, which can fail to locate optimum parameters, because it is impossible to describe a possible effect of interactions between factors (Gupta et al. 2004; Teng and $\mathrm{Xu}$ 2008; Fabiszewska et al. 2015). The DoE method has been applied to optimise the synthesis of lipase by Yarrowia lipolitica (Fabiszewska et al. 2015).

The aim of this study was to determine the potential for biosynthesis of propionic acid and vitamin B12 by $P$. freudenreichii strain T82 and apply an unconventional statistical approach to develop the optimal composition of sugars in the medium which might stimulate high production of metabolites by this strain. The three selected carbon sources were glucose, fructose and saccharose (as these are present in apple pomaces, which will be used as carbon sources in future studies), and the optimal relative proportions of those substrates were evaluated in Mixture Design experiments (Table 1).

\section{Materials and methods}

Inoculum preparation

The $P$. freudenreichii wild strain $\mathrm{T} 82$ from the collection of the Division of Biotechnology and Food Microbiology at Warsaw University of Life Science was used in the experiments.

The inoculum was prepared in a liquid VL $(\mathrm{POCH})$ medium containing $2 \%$ glucose $(\mathrm{pH} 7.0)$. Inoculation cultures were carried out in $50 \mathrm{ml}$ medium in Erlenmeyer flasks at $30{ }^{\circ} \mathrm{C}$ for $48 \mathrm{~h}$. The inoculum for the production media was $10 \%$ of the media volume (v/v).

Production media and growth conditions

The production medium included carbon sources (different proportions, Table 1), peptone (10 g/L), 
Table 1 Composition of sugars in model mediums

\begin{tabular}{lclllllrrrr}
\hline Nr of medium & I & II & III & IV & V & VI & VII & VIII & IX & X \\
\hline Carbon sources (g/L) & & & & & & & & & \\
Glucose & 25 & - & - & 12.5 & 12.5 & - & 16.6 & 4.2 & 4.2 & 8.33 \\
Frctose & - & 25 & - & 12.5 & - & 12.5 & 4.2 & 16.6 & 4.2 & 8.33 \\
Saccharose & - & - & 25 & - & 12.5 & 12.5 & 4.2 & 4.2 & 16.6 & 8.34 \\
\hline
\end{tabular}

yeast extract (5 g/L), L-cysteine hydrochloride $(0.4 \mathrm{~g} /$ $\mathrm{L})$, potassium hydrogen phosphate $(1.5 \mathrm{~g} / \mathrm{L})$ and dipotassium hydrogen phosphate $(2.5 \mathrm{~g} / \mathrm{L})$. The initial acidity $(\mathrm{pH})$ was 7.0. Cultures were carried out in $500 \mathrm{ml}$ flasks containing $250 \mathrm{~mL}$ medium for $120 \mathrm{~h}$ at $30{ }^{\circ} \mathrm{C}$, with $60 \mathrm{~h}$ under anaerobic conditions and $60 \mathrm{~h}$ under aerobic conditions (120 revolutions/min). The acidity of the medium during the fermentation process was adjusted every $12 \mathrm{~h}$ to $\mathrm{pH} 7.0$ with $30 \% \mathrm{NaOH}$ (acid neutralisation). The growth of bacteria in the medium was determined by measuring the optical density of the culture at $\lambda=550 \mathrm{~nm}$ (spectrophotometric method).

\section{Vitamin B12 analysis}

Quantitative determination of intracellular vitamin B12 produced by $P$. freudenreichii T82 was performed using a microbial assay in amicroplate format, the VitaFast ${ }^{\circledR}$ Vitamin B12 assay (R-Biopharm). Vitamin B12 was extracted from biomass produced, acetate buffer and $1 \% \mathrm{NaCN}$ were added to $1 \mathrm{~g}$ of biomass, the resulting mixture was shaken and subjected to a temperature of $95{ }^{\circ} \mathrm{C}$, and finally the extract was diluted. In order to obtain the biomass yield, liquid culture was taken into previously dried and weighed centrifuge tubes. Samples were then centrifuged for $10 \mathrm{~min}(5600 \times \mathrm{g})$. The supernatant was decanted and the biomass obtained was dried at $70{ }^{\circ} \mathrm{C}$ for about $24 \mathrm{~h}$ to obtain a constant mass. Dried biomass was weighed and the result of the biomass yield was expressed as $\mathrm{g} / \mathrm{L}$. The medium and the diluted extract were added to the wells of the microplate coated with Lactobacillus delbrueckii subspecies lactis (leishmanii). The growth yield of $L$. delbrueckii depends on the amount of vitamin B12 in the culture environment as the bacteria grow until the entire vitamin B12 source is consumed. Samples were incubated in the dark at $37{ }^{\circ} \mathrm{C}$ for $48 \mathrm{~h}$. Correlation of the growth of bacteria to levels of extracted vitamin B12 was measured in the form of turbidity (spectrophotometric measurement) and was read from a standard curve. Spectrophotometric measurements were made on a Bioscreen $\mathrm{C}$ microplate reader with a $540-650 \mathrm{~nm}$ filter.

Determination of organic acids

Quantitative analysis of propionic and acetic acids obtained from fermentation was carried out using a gas chromatography with a flame ionization detector (GCFID). Prior to the extraction of the acids, $25 \%$ sulfuric (VI) acid was added to the medium to release free organic acids from sodium propionate and sodium acetate (which resulting from alkalisation). The carboxylic acid fraction was extracted from the medium using a mixture of hexane (Avantor) and diethyl ether (Avantor) (1/1, v/v). The chromatographic separation was performed on a ZB-WAXplus column $(30 \mathrm{~m} \times 0.25 \mathrm{~mm} \times 0.25 \mu \mathrm{m})$. Quantitative calculations were made with respect to an internal standard (undecanoic acid-C11:0, Sigma Aldrich) using correction factors. The acid quality analysis was performed based on a comparison of the retention times of the tested samples with the retention times of standards.

Sugar analysis

The determination of the usage of reducing sugars by $P$. freudenreichii T82 bacteria was carried out using the 3.5-dinitrosalicylic acid (DNS) (the Miller method; Miller 1959). The principle of the method consists in the reducing effect of sugars present in the sample, which in an alkaline medium reduces the nitro groups of DNS to amino groups, the resulting amine derivatives are orange, and the intensity of the colouration is proportional to the sugar concentration of the tested sample. First, $1 \mathrm{~mL}$ of the solutions to be analysed was measured into test tubes, whilst $1 \mathrm{~mL}$ of distilled water was added to the control sample. Next, $1 \mathrm{~mL}$ of DNS and $5 \mathrm{~mL}$ of distilled water were added to all tubes and the contents of the tubes were mixed 
and placed in a boiling water bath for $5 \mathrm{~min}$. After this time, the samples were cooled down and their absorbance was measured at $\lambda=550 \mathrm{~nm}$. Saccharose containing samples were hydrolysed. The content of the reducing sugars in the analysed samples was read from a standard curve. To prepare the calibration curves, 8 solutions of glucose were prepared in the range $1-8 \mathrm{mg} / \mathrm{mL}$ (as described above).

Statistical analysis

All experiments were performed in triplicate. The computer software Excel 2013 for Windows 10 and STATISTICA 10.0 for StatSoft. Inc. were used for mathematical and statistical calculations. Due to the need to perform multiple combinations of the three selected substrates, we used the mixture design method of DoE (Design of Experiment) as a tool to facilitate optimising the composition of carbon sources in the culture medium. The significance level was 0.05 . In the experiments, simplex plans for the ternary mixtures were used.

\section{Results and discussion}

In this study we used $P$. freudenreichii T82 strain for several reasons. Firstly, our preliminary studies have shown that this strain is the most promising for the production of propionic acid from pure sugars and apple pomaces, among all of others tested (Piwowarek et al. 2016). Furthermore, strains of $P$. freudenreichii have multiple enzymatic systems that allow them to use many carbon sources for metabolic processes (Deptula et al. 2017a). The literature also indicates that strains of $P$. freudenreichii are potentially more useful than the other bacteria of the genus Propionibacterium and relatives genus in the biosynthesis of propionic acid from pure carbon sources (sugars) and waste materials, and also have a metabolic system that makes possible to produce vitamin B12 (Yazdani and Gonzales 2007; Zhu et al. 2010; Khan et al. 2011; Chen et al. 2012; Deptula et al. 2017a). Moreover, $P$. freudenreichii strains have GRAS status granted by the US FDA (Food and Drug Administration), which allows the use of these bacterial cells and their metabolites in the production of food or animal feed. For example, P. freudenreichii is a dairy-associated bacterium, traditionally used in the production of Swiss type cheeses (Martens et al. 2002).

The growth of bacteria in a culture medium demonstrates the adaptation of microorganisms to specific conditions and their ability to use the nutrients provided, which serve the bacteria for a number of metabolic processes such as organic acid and vitamin B12 biosynthesis. For P. freudenreichii T82, a reduction of sugar content was observed in each of the tested media compared with the baseline (Table 2). The highest consumption of sugars $(91 \%)$ by P. freudenreichii $\mathrm{T} 82$ was found in glucose exclusive medium (medium \# I), which at the same time yielded the largest-among all variants-growth of bacteria (maximum OD value 2.8, Table 3). Increased consumption of carbon sources and substantial bacterial growth were observed in all types of media (media \# IV, V and VII) where glucose amounted to at least half the available sugars. The greater the percentage of glucose, the higher the growth of the bacteria and the increased consumption of total sugars, which was presumably due to preferential glucose consumption by the tested $P$. freudenreichii strain. The lowest consumption of sugars was found in the medium with a $2.5 \%$ saccharose $(27 \%$, medium \# III). The lowest growth (OD 1.4) was also observed in this medium (Table 3).

Piwowarek et al. (2016) presented results that suggested the sugars that exert the most beneficial effects on the growth of the same strain of $P$. freudenreichii are fructose, glucose and saccharose. However, these cultures were conducted in media in which the optimum $\mathrm{pH}$ (7.0 for Propionibacterium species) was established only before inoculation of the production media in order to determine the growth and productivity of $P$. freudenreichii T82 in a stressful environment associated with increasing acidity. The biosynthesis of propionic and acetic acids by members of the genus Propionibacterium is inhibited by their negative feedback. Acidification of the medium by the release of metabolites (propionic and acetic acids) into the environment limits the growth of the bacteria and their metabolic activity. To minimise the effect of negative feedback by the acids synthesised, in this study the media were neutralised every $12 \mathrm{~h}$ with $30 \%$ $\mathrm{NaOH}$. In addition to changing the sugar consumption profile, regular $\mathrm{pH}$ adjustment of the culture medium to 7.0 also improved the growth of the bacteria and significantly increased the production of propionic and 
Table 2 Changes in the content of carbon sources in media during propagation of Propionibacterium freudenreichii $\mathrm{T} 82$
During fermentation the $\mathrm{pH}$ was maintained at 7.0. Initial substrate concentration was $2.5 \%$

Table 3 Changes in optical density (OD) in media during propagation of Propionibacterium freudenreichii $\mathrm{T} 82$
During fermentation the $\mathrm{pH}$ was maintained at 7.0. Initial substrate concentration was $2.5 \%$

\begin{tabular}{|c|c|c|c|c|c|c|}
\hline \multicolumn{4}{|l|}{ Carbon sources } & \multicolumn{2}{|c|}{ Time (h) } & \multirow[t]{2}{*}{ Use $(\%)$} \\
\hline $\mathrm{Nr}$ of medium & \multicolumn{3}{|c|}{ Sugars ratio in mediums } & Carbon sources $(\mathrm{g} / \mathrm{L})$ & $\begin{array}{l}120 \\
\text { ources }(\mathrm{g} / \mathrm{L})\end{array}$ & \\
\hline I & 1 & 0 & 0 & 25 & $2.3 \pm 0.0$ & 91 \\
\hline II & 0 & 1 & 0 & 25 & $14.1 \pm 0.2$ & 43.7 \\
\hline III & 0 & 0 & 1 & 25 & $18.2 \pm 0.1$ & 27.1 \\
\hline IV & 0.5 & 0.5 & 0 & 25 & $7.6 \pm 0.2$ & 69.5 \\
\hline $\mathrm{V}$ & 0.5 & 0 & 0.5 & 25 & $10.5 \pm 0.2$ & 57.9 \\
\hline VI & 0 & 0.5 & 0.5 & 25 & $17.4 \pm 0.3$ & 30.4 \\
\hline VII & 0.664 & 0.168 & 0.168 & 25 & $7.7 \pm 0.1$ & 69.3 \\
\hline VIII & 0.168 & 0.664 & 0.168 & 25 & $16.1 \pm 0.0$ & 35.4 \\
\hline IX & 0.168 & 0.168 & 0.664 & 25 & $16.3 \pm 0.1$ & 34.6 \\
\hline $\mathrm{X}$ & 0.33 & 0.33 & 0.34 & 25 & $14.1 \pm 1.0$ & 43.7 \\
\hline
\end{tabular}

\begin{tabular}{|c|c|c|c|c|c|}
\hline \multirow[t]{2}{*}{$\mathrm{Nr}$} & \multicolumn{5}{|l|}{ Time (h) } \\
\hline & $\begin{array}{l}24 \\
\text { OD }\end{array}$ & 48 & 72 & 96 & 120 \\
\hline I & $1.4 \pm 0.0$ & $2.1 \pm 0.0$ & $2.4 \pm 0.1$ & $2.8 \pm 0.1$ & $2.8 \pm 0.1$ \\
\hline II & $0.9 \pm 0.0$ & $1.2 \pm 0.0$ & $1.3 \pm 0.0$ & $1.5 \pm 0.0$ & $1.5 \pm 0.0$ \\
\hline III & $0.8 \pm 0.1$ & $1.1 \pm 0.1$ & $1.3 \pm 0.1$ & $1.4 \pm 0.0$ & $1.4 \pm 0.0$ \\
\hline IV & $1.4 \pm 0.0$ & $1.8 \pm 0.0$ & $2,0 \pm 0.1$ & $2.3 \pm 0.2$ & $2.1 \pm 0.2$ \\
\hline V & $1.4 \pm 0.1$ & $1.9 \pm 0.0$ & $2.1 \pm 0.1$ & $2.2 \pm 0.0$ & $2.1 \pm 0.1$ \\
\hline VI & $0.9 \pm 0.0$ & $1.1 \pm 0.0$ & $1.3 \pm 0.0$ & $1.5 \pm 0.0$ & $1.5 \pm 0.0$ \\
\hline VII & $1.4 \pm 0.0$ & $1.6 \pm 0.0$ & $1.8 \pm 0.0$ & $2.1 \pm 0.0$ & $2.1 \pm 0.0$ \\
\hline VIII & $1.2 \pm 0.0$ & $1.5 \pm 0.0$ & $1.9 \pm 0.0$ & $2.0 \pm 0.0$ & $2.0 \pm 0.1$ \\
\hline IX & $0.8 \pm 0.0$ & $1.2 \pm 0.0$ & $1.5 \pm 0.0$ & $1.6 \pm 0.0$ & $1.5 \pm 0.0$ \\
\hline X & $1.4 \pm 0.1$ & $1.6 \pm 0.1$ & $1.8 \pm 0.0$ & $1.9 \pm 0.1$ & $1.9 \pm 0.0$ \\
\hline
\end{tabular}

acetic acids. Piwowarek et al. (2016) reported that the sum of these two acids produced in glucose containing medium was about $5 \mathrm{~g} / \mathrm{L}$, but with a regular alkalisation of the culture medium, the total acid content was here close to $53 \mathrm{~g} / \mathrm{L}$. In the 2016 study, the sugar that has the greatest influence on bacterial growth was fructose, compared with glucose in the present study. In addition to the carbon source, there are other factors that can significantly determine the result of the experiment and which are not included in the optimisation and modeling processes, such as the physiological state of bacterial cells in the inoculum or the environmental conditions of the cell culture, for example, pH. In both Piwowarek et al. (2016) and the present experiments, saccharose was the sugar that least supported bacterial growth. Most likely, this is because the hydrolysis of this disaccharide into simple sugars is related, among other things, to the production of suitable enzymes and increased energy input. Thus, it is easier for bacteria to use monosaccharides when available.

Tables 4 and 5 show the course of propionic and acetic acids production by fermentation in the 10 tested media. The percentage of propionic and acetic acids varied during the fermentation process. The maximum production of the two metabolites by the tested bacterial strain, regardless of the culture conditions, was at $120 \mathrm{~h}$. The highest concentration of produced acids was found in the media in which glucose accounted for at least $50 \%$ of the available carbon sources (\# I, IV, and VII, Tables 3 and 4). P. freudenreichii strain $\mathrm{T} 82$ produced the smallest amount of acids in media \# III and IV, that is, in the media in which the dominant carbon source was 
Table 4 Production of acetic acid by the Propionibacterium freudenreichii $\mathrm{T} 82$ strain

\begin{tabular}{|c|c|c|c|c|c|}
\hline \multirow[t]{3}{*}{$\mathrm{Nr}$} & \multicolumn{5}{|l|}{ Time (h) } \\
\hline & 24 & 48 & 72 & 96 & 120 \\
\hline & \multicolumn{5}{|c|}{ Production of acetic acid (g/L) } \\
\hline I & $2.8 \pm 3.0$ & $5.1 \pm 0.4$ & $6.5 \pm 1.4$ & $11.4 \pm 2.3$ & $12.4 \pm 0.6$ \\
\hline II & $0.5 \pm 0.1$ & $0.6 \pm 0.3$ & $1.5 \pm 0.9$ & $1.7 \pm 0.2$ & $3.2 \pm 0.5$ \\
\hline III & $0.5 \pm 0.0$ & $0.6 \pm 0.3$ & $1.1 \pm 0.5$ & $1.2 \pm 0.4$ & $2.3 \pm 1.8$ \\
\hline IV & $0.6 \pm 0.3$ & $3.1 \pm 1.0$ & $5.8 \pm 2.1$ & $3.7 \pm 0.5$ & $7.6 \pm 0.8$ \\
\hline $\mathrm{V}$ & $0.5 \pm 0.2$ & $1.3 \pm 0.3$ & $1.6 \pm 0.8$ & $4.9 \pm 0.7$ & $8.2 \pm 5.0$ \\
\hline VI & $0.6 \pm 0.1$ & $0.8 \pm 0.2$ & $1.1 \pm 0.6$ & $1.7 \pm 0.0$ & $2.8 \pm 0.4$ \\
\hline VII & $0.6 \pm 0.4$ & $0.7 \pm 0.7$ & $1.2 \pm 1.1$ & $3.6 \pm 1.1$ & $10.6 \pm 0.3$ \\
\hline VIII & $0.5 \pm 0.3$ & $0.5 \pm 0.8$ & $0.6 \pm 0.0$ & $1.4 \pm 0.0$ & $3.4 \pm 0.4$ \\
\hline IX & $0.4 \pm 0.1$ & $0.4 \pm 0.0$ & $0.9 \pm 0.0$ & $2.5 \pm 0.2$ & $3.3 \pm 0.8$ \\
\hline$X$ & $0.5 \pm 0.1$ & $1.0 \pm 0.2$ & $1.9 \pm 0.9$ & $1.3 \pm 0.4$ & $6.2 \pm 0.1$ \\
\hline
\end{tabular}

\begin{tabular}{|c|c|c|c|c|c|}
\hline $\mathrm{Nr}$ & $\begin{array}{l}\text { Time (h) } \\
24 \\
\text { Production }\end{array}$ & $\begin{array}{l}48 \\
\text { opionic acic }\end{array}$ & 72 & 96 & 120 \\
\hline I & $2.9 \pm 1.6$ & $5.9 \pm 0.4$ & $15.1 \pm 6.1$ & $29.0 \pm 5.8$ & $40.4 \pm 1.2$ \\
\hline II & $0.6 \pm 0.2$ & $0.6 \pm 0.3$ & $2.0 \pm 0.6$ & $5.3 \pm 1.4$ & $12.1 \pm 0.5$ \\
\hline III & $0.6 \pm 0.4$ & $0.7 \pm 0.5$ & $2.0 \pm 0.7$ & $3.7 \pm 2.0$ & $5.1 \pm 2.8$ \\
\hline IV & $1.1 \pm 0.5$ & $2.4 \pm 0.5$ & $8.1 \pm 2.8$ & $15.4 \pm 2.8$ & $23.9 \pm 1.1$ \\
\hline V & $1.2 \pm 1.9$ & $2.7 \pm 1.3$ & $6.8 \pm 2.6$ & $11.5 \pm 2.3$ & $15.8 \pm 2.2$ \\
\hline VI & $0.6 \pm 0.3$ & $0.8 \pm 0.2$ & $1.9 \pm 0.7$ & $2.3 \pm 0.2$ & $5.7 \pm 1.8$ \\
\hline VII & $0.4 \pm 0.6$ & $2.8 \pm 1.1$ & $4.0 \pm 0.3$ & $7.3 \pm 2.4$ & $23.2 \pm 2.8$ \\
\hline VIII & $0.9 \pm 0.1$ & $2.9 \pm 0.2$ & $3.8 \pm 1.2$ & $5.4 \pm 1.3$ & $13.5 \pm 2.0$ \\
\hline IX & $0.8 \pm 0.1$ & $1.6 \pm 0.2$ & $3.0 \pm 0.3$ & $4.9 \pm 0.4$ & $11.5 \pm 0.3$ \\
\hline$X$ & $1.3 \pm 0.1$ & $3.3 \pm 0.5$ & $5.8 \pm 0.2$ & $9.8 \pm 0.7$ & $16.2 \pm 0.8$ \\
\hline
\end{tabular}

Table 5 Production of propionic acid by the Propionibacterium freudenreichii $\mathrm{T} 82$ strain
During fermentation the $\mathrm{pH}$ was maintained at 7.0. Initial substrate concentration was $2.5 \%$
During fermentation the $\mathrm{pH}$ Initial substrate concentration was $2.5 \%$

During fermentation the pH
was maintained at 7.0 .
Initial substrate
concentration was $2.5 \%$

saccharose. Statistical analysis of the data fror propionic acid production by $P$. freudenreichii $\mathrm{T} 82$ showed that glucose (Figs. 1 and 2) was the sugar most important for the biosynthesis of this compound. Based on the results obtained, the use of sugar mixtures led to a reduction in acid production. The greater the percentage of glucose in the medium, the more efficient the biosynthesis of propionic and acetic acids. For the production of these metabolites by $P$. freudnreichii $\mathrm{T} 82$, glucose and fructose were found to be statistically significant. The statistical model obtained for the production of propionic acid by $P$. freudenreichii $\mathrm{T} 82$ strain was matched at $90 \%$ to the observed data (Fig. 2), so the model describes quite well the significant effect of carbon sources on the metabolic activity, and is also characterised by good prognostic abilities. This will enable the optimisation

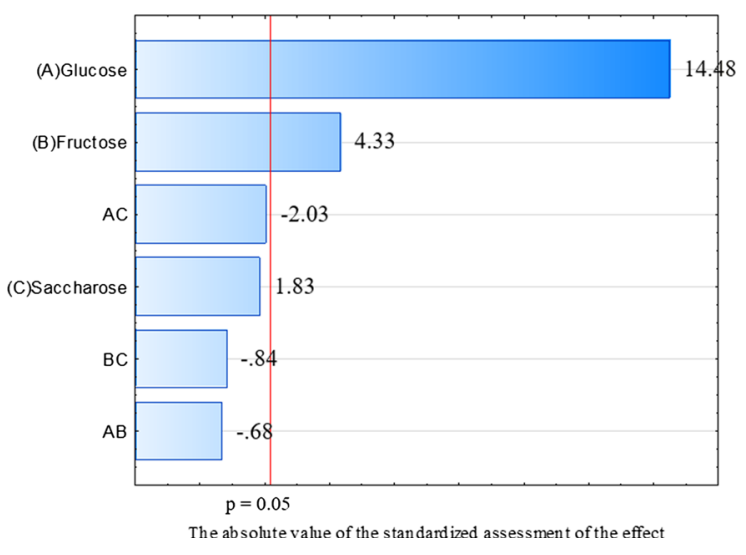

Fig. 1 Pareto diagram showing the influence of the investigated factors on propionic acid production by $P$. freudenreichii $\mathrm{T} 82$ in $120 \mathrm{~h}$ of culture 


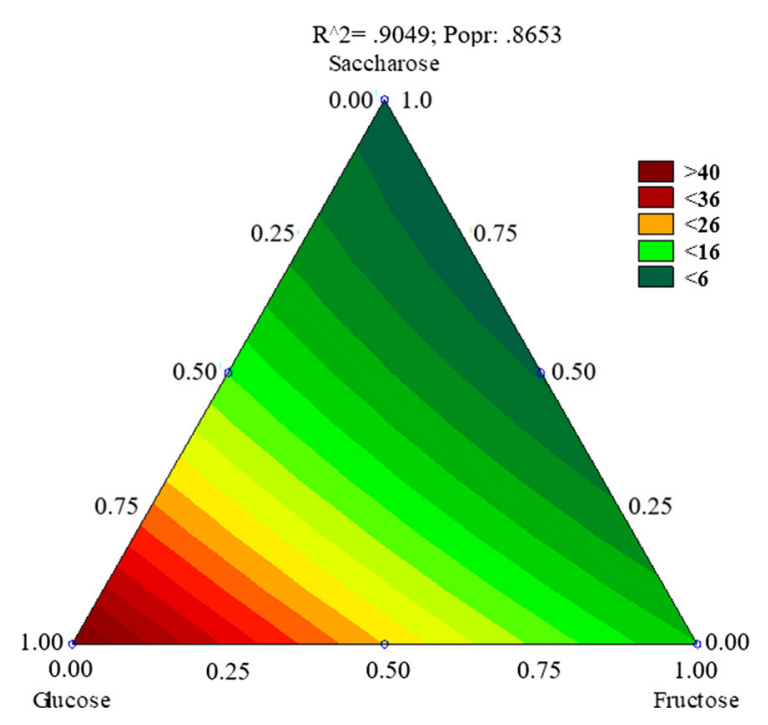

Fig. 2 Contour plot demonstrating production of propionic acid by $P$. freudenreichii T82 depending on the composition of the carbon source in medium. The results obtained for medium I-X according to Table 5 were taken into account

of the composition of carbon sources in media containing waste materials such as apple pomaces.

In this study, $P$. freudenreichii T82 strain has been shown to produce significant amounts of propionic acid from glucose as the sole carbon source. The theoretical yield of propionic acid production from glucose should be $0.55 \mathrm{~g}$ propionic acid/g substrate (Wang and Yang 2013). P. freudenreichii T82 strain could yield this metabolite at a rate of $1.6 \mathrm{~g} / \mathrm{g}$, almost 3 times higher than the theoretical yield and that $(0.43 \mathrm{~g} /$ g) obtained by Wang and Yang (2013). The difference between the yields of propionic acid synthesis could be due to several reasons. One of them may be a naturally higher yield of propionic acid production by a particular bacterial strain. In addition, attention should be paid to differences in the applied culture parameters. Wang and Yang (2013) ran fermentations using $P$. freudenreichii subsp. shermanii DSM 4902 for $120 \mathrm{~h}$ at $32{ }^{\circ} \mathrm{C}$ and $\mathrm{pH} 6.5$ (the $\mathrm{pH}$ was not stabilised during the process) and the initial glucose concentration was $3 \%$. However, the present experiments used a temperature of $30^{\circ} \mathrm{C}$, a growth period of $120 \mathrm{~h}$, a pH of 7.0 (pH neutralised every $12 \mathrm{~h}$ ), and a carbon source concentration of $2.5 \%$.

Optimal conditions for growth and metabolic activity of Propionibacterium species are typically $30{ }^{\circ} \mathrm{C}$ and $\mathrm{pH}$ 7.0. The use of other parameters may reduce the production of propionic acid. Failure to stabilise the $\mathrm{pH}$ in the Wang and Yang (2013) study likely caused accumulation of acids during the fermentation, which, by reducing the $\mathrm{pH}$, had a negative impact on the growth and metabolism of the producer cells. Furthermore, a higher concentration of sugar $(30 \mathrm{~g} / \mathrm{L})$, and therefore higher osmotic pressure of the culture medium, could adversely affect the cells.

Kośmider et al. (2010) used P. freudenreichii subsp. shermani for fermentations conducted in media supplemented with glucose. Total sugar consumption occurred after $48 \mathrm{~h}$. Synthesis of propionic acid reached $10.2 \mathrm{~g} / \mathrm{L}$ with an efficiency of $0.5 \mathrm{~g}$ of propionic acid per gram of substrate. More propionic acid (15.7 g/L) was obtained by Zhu et al. (2010) after $120 \mathrm{~h}$ of fermentation. In comparison to the studies conducted by Kośmider et al. (2010) and Zhu et al. (2010) the amount of propionic acid obtained using $P$. freudenreichii $\mathrm{T} 82$ is high, confirming it. In contrast, Chen et al. (2012) obtained significantly higher concentrations of propionic acid ( $>136 \mathrm{~g} / \mathrm{L})$ using immobilised $P$. freudenreichii strain CCTCC M207015 grown on sugar cane stalks.I Immobilisation also caused morphological changes in the bacterial cells including a threefold increase in length, decrease in diameter, and increase in surface area, which most likely allowed the more efficient absorption of nutrients from the media. Immobilisation may have also increased the resistance pf the strain to an acidified environment and limited the effect of negative feedback by propionic acid. Suwannakham and Yang (2005) came to similar conclusions. They immobilised a culture of $P$. acidipropionici ATCC 4875 inside a bioreactor, in order to reduce the effect of the acids on the metabolic activity of bacteria. Immobilised cells produced $20-59 \%$ more propionate $(71.8 \mathrm{~g} / \mathrm{L}), 17 \%$ less acetic acid and $50 \%$ less succinate compared to free cells.

Industrial production of vitamin B12 is based on fermentation processes using microorganisms, mainly genetically modified $P$. denitrificans (Blanche et al. $1995,1998)$ which, due to the high efficiency of synthesis, accounts for $80 \%$ of global demand (Blanche et al. 1989; Miyano et al. 2000; Roman et al. 2001). The use of genetically modified microorganisms, however, raises a number of problems in social acceptance. For many years, various ways of efficient and industrially profitable production of vitamin B12 using non-genetically engineered 
microorganisms have been sought. Such research focuses on selection of suitable strains, carbon sources and culture methods (Quesada-Chanto et al. 1994; Gardner and Champagne 2005; Yu et al. 2015).

Among consumers, interest in food products enriched with therapeutic compounds such as vitamin B12 produced by in situ fermentation is growing. $P$. freudenreichii strains that produce therapeutically active vitamin B12 (with 5.6-dimethylbenzimidazole [DMBI] as the lower ligand in cobalamin) is of particular importance (Deptula et al. 2015, 2017b). Moreover, it has GRAS status, enabling the use of live cells in food and feed products.

In case of the production of vitamin B12 by $P$. freudenreichii $\mathrm{T} 82$, the results were quite different (Table 6). In the media where the growth of bacteria and acid production were the least, that is, in media III and $\mathrm{V}$, the highest production of vitamin $\mathrm{B} 12$ was found, close to $1.4 \mu \mathrm{g} / 100 \mathrm{~mL}$. Conversely, in media where growth and acid production was the highest (media \# I and IV), the lowest production of cobalamin was found, $\sim 0.3 \mu \mathrm{g} / 100 \mathrm{~mL}$ (Table 6). This is most probably because the optimum $\mathrm{pH}$ for the production of vitamin B12 by the $P$. freudenriechia T82 strain is 7.0. Although the $\mathrm{pH}$ of the media was neutralised every $12 \mathrm{~h}$, there was a sharp decrease in the $\mathrm{pH}$ between the neutralising steps, especially in the media

Table 6 Production of vitamin B12 by the Propionibacterium freudenreichii $\mathrm{T} 82$ strain

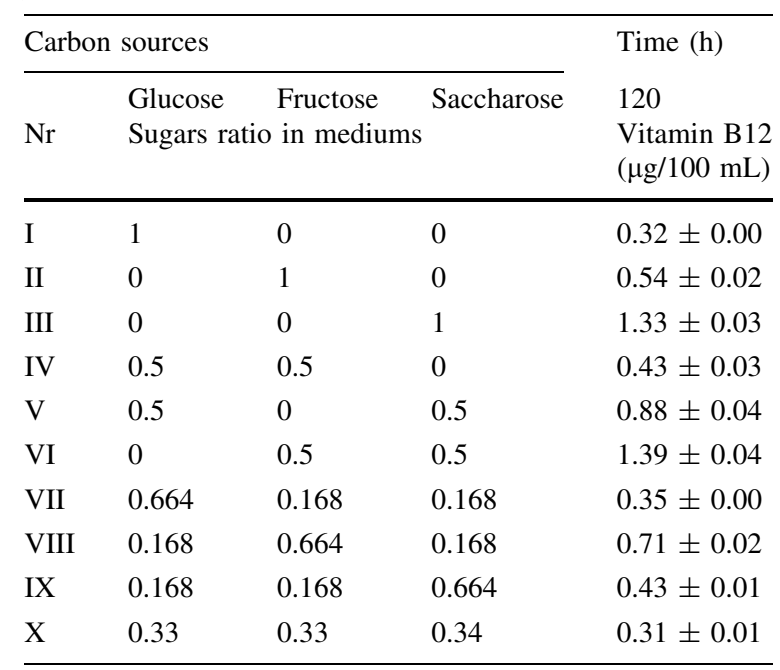

During fermentation the $\mathrm{pH}$ was maintained at 7.0. Initial substrate concentration was $2.5 \%$ where acid biosynthesis was most notable (medium \# IV), and thus there was disturbance of optimum conditions for cobalamin biosynthesis by P. freudenreichii $\mathrm{T} 82$. Vitamin $\mathrm{B} 12$ is used by propionic acid bacteria as a cofactor of the enzymatic reaction for the production of propionic acid. Coenzyme B12 and methylmalonyl CoA mutase are responsible for converting succinyl-CoA into methylmalonyl-CoA, which is the penultimate intermediate in the propionate biosynthesis pathway. With the increased production of propionic acid (media \# I and IV), the consumption of cobalamin increases for the aforementioned reaction, which in turn leads to a decrease in the vitamin B12 yield. The statistical analysis of the results of vitamin B12 production showed that the sugar most important for the biosynthesis of this compound by $P$. freudenreichii T82 was saccharose (Figs. 3 and 4). The addition of glucose and/or fructose resulted in reduced metabolite production. In the medium in which saccharose formed at least $50 \%$ of sugars, increased production of cobalamin, reduced acid production, and reduced sugar consumption compared with the other media was observed. The increased synthesis of cobalamin in these media probably reflects the $\mathrm{pH}$ of the medium (close to 7.0, the optimum value for cobalamin biosynthesis) caused by the low content of propionic and acetic acids. In addition, because of the small amount of saccharose used for acid synthesis (preferential use of glucose), saccharose could be used to produce cobalamin. It may be that the use of saccharose as a carbon source

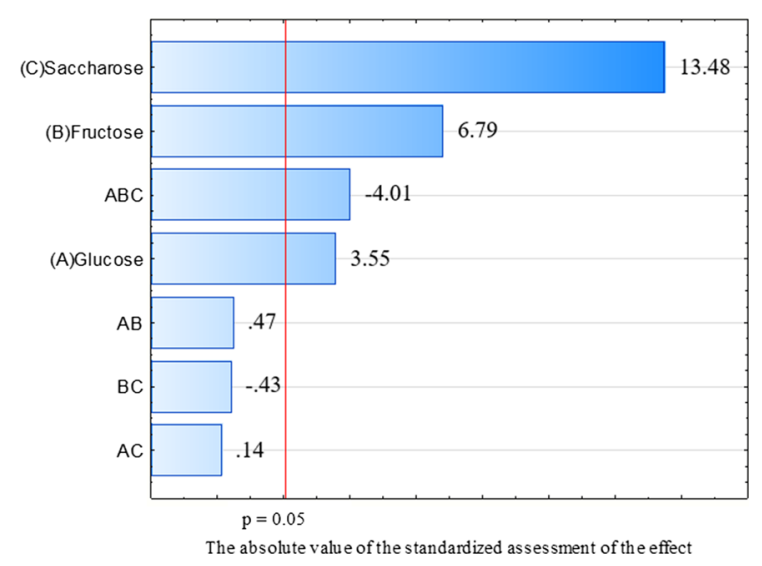

Fig. 3 Pareto diagram showing the influence of the investigated factors on vitamin B12 production by $P$. freudenreichii T82 in $120 \mathrm{~h}$ of culture 


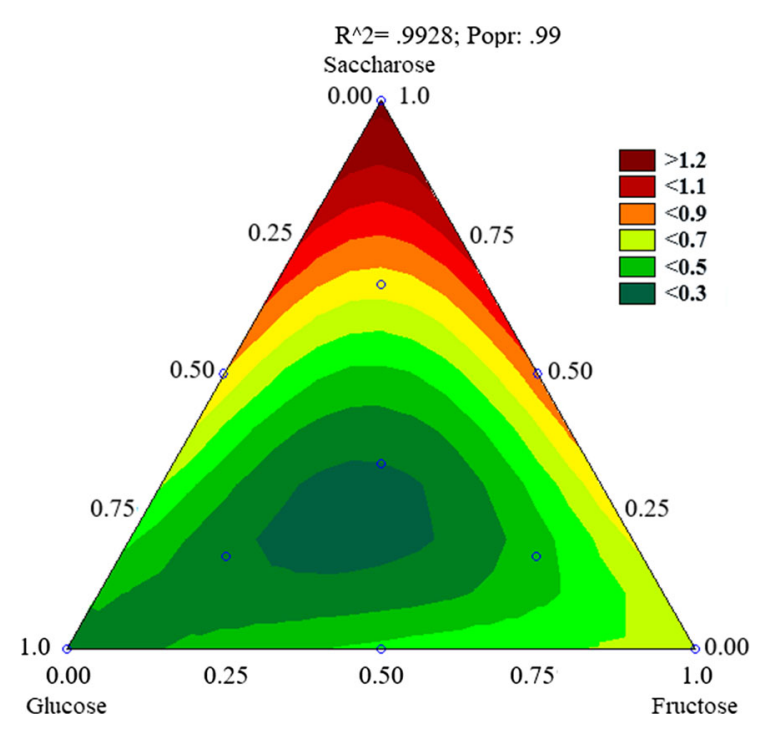

Fig. 4 Contour plot demonstrating production of vitamin B12 by $P$. freudenreichii T82 depending on the composition of the carbon source in medium. The results obtained for medium I-X according to Table 6 were taken into account

limits the production of acids and stimulates the biosynthesis of vitamins at the same time.

The amount of vitamin B12 obtained from $P$. freudenreichii strain T82, irrespective of the media used, did not indicate a natural ability to produce cobalamin with high efficiency, even though the $\mathrm{pH}$ was adjusted every $12 \mathrm{~h}$ and the temperature of the culture was maintained at an optimum level. Here the production media were not supplemented with compounds important for the production of cobalamin (such as cobalt ions, DMBI, glycine, threonine, 5-aminolevulinic, or choline), in order to determine the natural ability for synthesis of this vitamin by $P$. freudenreichii $\mathrm{T} 82$. Therefore it seems, in order to improve the efficiency of vitamin B12 biosynthesis by this strain, production media should be enriched in cobalamin biosynthesis precursors to direct metabolism towards the production of this specific metabolite (Roman et al. 2001; Murooka et al. 2005; Thirupathaiah et al. 2012; Kośmider et al. 2012; Wang et al. 2015; Deptula et al. 2017b). Chamlagain et al. (2016) investigated the effect of addition of DMBI precursors (riboflavin $[\mathrm{RF}]$ and nicotinamide $[\mathrm{NAM}]$ ) and DMBI alone on the production of vitamin $\mathrm{B} 12$ by $P$. freudenreichii. Supplementation of media with riboflavin $(40 \mathrm{mM})$ and nicotinamide $(27 \mathrm{mM})$ increased the yield of cobalamin fourfold as compared with that in control cultures, as did supplementation with DMBI (100 mM).

To increase the production of vitamin B12 by $P$. freudenreichii T82 strain, it is likely necessary to inhibit acid biosynthesis or to remove them from the culture medium, for example, by fermentation combined with purification in an activated carbon absorption column, extractive fermentation, electrodialysis, or the use of immobilised cells. Growth of $P$. freudenreichii T82 in larger volumes of production medium in an appropriately controlled, bioreactor environment could also improve the productivity of cobalamin biosynthesis. Wang et al. (2015) examined the effect of propionic acid and DMBI on vitamin B12 biosynthesis by $P$. freudenreichii during fermentation combined with purification in an absorption column in a bioreactor medium. They found that maintaining a concentration of propionic acid at the initial stage of fermentation at $10-20$ and $20-30 \mathrm{~g} / \mathrm{L}$ at a later stage can effectively increase cobalamin production, to $58.8 \mathrm{mg} / \mathrm{L}$. Wang et al. (2012) examined an expanded bed adsorption bioreactor for the simultaneous biosynthesis of propionic acid and vitamin $\mathrm{B} 12$ by $P$. freudenreichii CICC 10019. They succeeded in recovering propionic acid by semi-continuous recirculation of the unfiltered broth, eliminating the feedback effect of this metabolite, which resulted in concentrations of propionic acid and vitamin $\mathrm{B} 12$ of $52.5 \mathrm{~g} / \mathrm{L}$ and $43.04 \mathrm{mg} / \mathrm{L}$, respectively. Vitamin B12 production by P. freudenreichii $\mathrm{T} 82$ could also be improved by using more suitable carbon sources. Wang et al. (2014) were able to produce high yields of vitamin B12 $(0.72 \mathrm{mg} /$ g) and propionic acid $(0.81 \mathrm{~g} / \mathrm{g})$ in $P$. freudenreichii subsp. shermanii using concurrent glucose and glycerol fermentation.

One of the major problems of most industrial plants is finding uses for the by-products of technological processes. Therefore, innovative waste management solutions such as biotechnology are being sought. The biotechnological use of bacteria may reduce the pollution of the environment not only by waste disposal, but also by converting it into useful and valuable industrial ingredients. The high yield of propionic acid biosynthesis by $P$. freudenreichii T82 provides an approach for the use of this strain to naturally obtain this compound, which is currently produced mainly by expensive and environmentally harmful petrochemical processes (e.g. hydrocarboxylation of ethylene). The cost of acquiring one ton of 
propionic acid via biotechnological process using microorganisms reaches up to US $\$ 2000$, which is 2 times the cost of chemical acid production. However, due to scarcity of resources, serious environmental damage resulting from the current production and a growing demand for natural and organic food, there is a growing interest in obtaining propionic acid using microorganisms and using waste materials from various industries as media (which should reduce the cost of acid production) (Baumann and Westermann 2016). In order to make the tested strain of $P$. freudenreichii T82 useful for industrial production, further research is needed on the selection of a suitable carbon source in the form of waste materials that contain significant quantities of glucose and fructose (as in apple pomaces) and to determine culture methods which allow for increased production of acid (e.g. immobilisation or growth in a bioreactor). $P$. freudenreichii $\mathrm{T} 82$ can also produce cobalamin, but the efficiency of this process is lower. Further studies on the biosynthesis of this metabolite by the $P$. freudenreichii $\mathrm{T} 82$ strain are needed, such as the optimisation of culture conditions (e.g. suitable carbon sources, biostimulators), maintaining cultured cells, or the regulation of biosynthesis of organic acids resulting from the fermentation, for example, by using carbon source limiting their production and stimulating the vitamin biosynthesis. Statistical analysis (DoE) of the results obtained allowed us to determine which sugars (carbon sources) exert the most beneficial influence on the biosynthesis of propionic acid and cobalamin. This will allow for the selection of appropriate quantities of apple pomaces and, as a result, the culture medium based on these waste materials will contain optimum concentrations of suitable sugars, thus improving the efficiency of propionic acid and vitamin $\mathrm{B} 12$ production by $P$. freudenreichii $\mathrm{T} 82$.

The datasets during and/or analysed during the current study are available from the corresponding author on reasonable request.

Acknowledgements This research was funded by the Warsaw University of Life Sciences SGGW (WULS-SGGW) (No. 505-10-092800-N00295-99).

\section{Compliance with ethical standards}

Conflict of interest The authors declare no conflict of interest.
Ethical approval This article does not contain any studies with human or animal subjects.

Open Access This article is distributed under the terms of the Creative Commons Attribution 4.0 International License (http:// creativecommons.org/licenses/by/4.0/), which permits unrestricted use, distribution, and reproduction in any medium, provided you give appropriate credit to the original author(s) and the source, provide a link to the Creative Commons license, and indicate if changes were made.

\section{References}

Barbirato F, Chedaille D, Bories A (1997) Propionic acid fermentation from glycerol: comparison with conventional substrates. Appl Microbiol Biotechnol 47:441-446. https:// doi.org/10.1007/s002530050953

Baumann I, Westermann P (2016) Microbial production of short chain fatty acids from lignocellulosic biomass: current processes and market. BioMed Res Int. https://doi.org/10. $1155 / 2016 / 8469357$

Blanche F, Debussche L, Thibaut D, Crouzet J, Cameron B (1989) Purification and characteriztationof S-adenosyl-Lmethionine: uroporphyrinogen III methyltransferase from Pseudomonas denitrificans. J Bacteriol 171:4222-4231

Blanche F, Cameron B, Crouzet J, Debussche L, Thibaut D, Vuilhorgne M, Lepper FJ, Battersby AR (1995) Vitamin B12: how the problem of its biosynthesis was solved. Angew Chem Int Ed Engl 34:383-411. https://doi.org/10. 1002/anie. 19950383

Blanche F, Cameron B, Crouzet J, Debussche L, Levy-Schil S, Thibaut D (1998) Rhône- Poulenc Biochimie. Eur Patent 0516647:B1

Carrondo MJ, Crespo JP, Moura M (1988) Production of propionic acid using a xylose utilizing Propionibacterium. Appl Biochem Biotechnol 17:295-312. https://doi.org/10. 1007/BF02779164

Chamlagain B, Deptula P, Edelmann M, Kariluoto S, Grattepanche F, Lacroix C, Varmanen P, Piironen V (2016) Effect of the lower ligand precursors on vitamin $\mathrm{B} 12$ production by food-grade Propionibacteria. LWT 72:117-124. https://doi.org/10.1016/j.lwt.2016.04.023

Chen F, Feng XH, Xu H, Zhang D, Ouyang PK (2012) Propionic acid production in a plant fibrous-bed bioreactor with immobilized Propionibacterium freudenreichii CCTCC M207015. J Biotechnol 164:202-210. https://doi.org/10. 1016/j.jbiotec.2012.08.025

Deptula P, Kylli P, Chamlagain B, Holm L, Kostiainen R et al (2015) BluB/CobT2 fusion enzyme activity reveals mechanisms responsible for production of active form of vitamin $\mathrm{B}_{12}$ by Propionibacterium freudenreichii. Microb Cell Fact 14:2-12. https://doi.org/10.1186/s12934-0150363-9

Deptula P, Laine PK, Richard J, Smolander OP et al (2017a) De novo assembly of genomes from long sequence reads reveals uncharted territories of Propionibacterium freudenreichii. BMC Genom 18:790. https://doi.org/10. 1186/s12864-017-4165-9 
Deptula P, Chamlagain B, Edelmann M, Sangsuwan P et al (2017b) Food-like growth conditions support production of active vitamin B12 by Propionibacterium freudenreichii 2067 without DMBI, the lower ligand base, or cobalt supplementation. Front Microbiol 368:1-11. https://doi. org/10.3389/fmicb.2017.00368

Fabiszewska A, Kotyrba D, Nowak D (2015) Assortment of carbon sources in medium for Yarrowia lipolytica lipase production: A statistical approach. Ann Microbiol 65(3):1495-1503. https://doi.org/10.1007/s13213-0140988-7

Feng X, Chen F, Xu H, Wu B, Li H, Li S, Ouyang P (2011) Green and economical production of propionic acid by Propionibacterium freudenreichii CCTCC M207015 in plant fibrous-bed bioreactor. Bioresour Technol 102:6141-6146. https://doi.org/10.1016/j.biortech.2011. 02.087

Gardner N, Champagne CP (2005) Production of Propionibacterium shermanii biomass and vitamin B12 on spent Media. J Appl Microbiol 99:1236-1245. https://doi.org/10. 1111/j.1365-2672.2005.02696.x

Gupta R, Gupta N, Rathi P (2004) Bacterial lipases: an overview of production, purification and biochemical properties. Appl Microbiol Biotechnol 64(6):763-781. https://doi.org/ $10.1007 / \mathrm{s} 00253-004-1568-8$

Gupta N, Sahai V, Gupta R (2007) Alkaline lipase from a novel strain Burkholderia multivorans: statistical medium optimization and production in a bioreactor. Process Biochem 42(4):518-526. https://doi.org/10.1016/j.procbio.2006.10. 006

Gwiazdowski R, Gwiazdowska D (2008) Oddziaływanie mieszanych kultur bakterii fermentacji propionowej i mlekowej na grzyby patogeniczne. Prog Plant Protection 48(2):719-723

Himmi EH, Bories A, Boussaid A, Hassani L (2000) Propionic acid fermentation of glycerol and glucose by Propionibacterium acidipropionici and Propionibacterium freudenreichii ssp. shermanii. Appl Microbiol Biotechnol 53:435-440. https://doi.org/10.1007/s002530051638

Hsu ST, Yang ST (1991) Propionic acid fermentation of lactose by Propionibacterium acidipropionici: effects of $\mathrm{pH}$. Biotechnol Bioeng 38:571-578. https://doi.org/10.1002/ bit.260380603

Huang YL, Wu Z, Zhang L, Ming Cheung C, Yang ST (2002) Production of carboxylic acids from hydrolyzed corn meal by immobilized cell fermentation in a fibrous-bed bioreactor. Bioresour Technol 82:51-59. https://doi.org/10. 1016/S0960-8524(01)00151-1

Khan MN, Mir NA, Khan MM (2011) Production of vitamin B 12 by improved strains of Propionibacterium freudenreichii. Biotechnol Bioinf Bioeng 1:19-24. https://doi.org/10. 1111/j.1365-2672.2005.02696.x

Kośmider A, Drożdżyńska A, Blaszka K, Leja K, Czaczyk K (2010) Propionic acid production by propionibacterium freudenreichii ssp. shermanii using crude glycerol and whey lactose industrial wastes. Pol J Environ Stud 19(6):1249-1253

Kośmider A, Białas W, Kubiak P, Drożdżyńska A, Czaczyk K (2012) Vitamin $B_{12}$ production from crude glycerol by Propionibacterium freudenreichii ssp. shermanii: optimization of medium composition through statistical experimental designs. Bioresour Technol 105:128-133. https://doi.org/10.1016/j.biortech.2011.11.074

Lewis VP, Yang ST (1992) A novel extractive fermentation process for propionic acid production from whey lactose. Biotechnol Prog 8:104-110. https://doi.org/10.1021/ bp00014a003

Martens JH, Barg H, Warren MJ, Jahn D (2002) Microbial production of vitamin B12. Appl Microbiol Biotechnol 58:275-285. https://doi.org/10.1007/s00253-001-0902-7

Mason RL, Gunst RF, Hess JL (1989) Statistical design and analysis of experiments. Wiley, Hoboken

Meile L, Dasen G, Miescher S, Stierli M, Teuber M (1999) Classification of propionic acid bacteria and approaches to applied genetics. Lait 79:71-78. https://doi.org/10.1051/ lait: 199915

Miller GL (1959) Use of dinitrosalicylic acid reagent for determination of reducing sugar. Anal Chem 31(3):426-428

Miyano K, Ye K, Shimizu K (2000) Improvement of vitamin B12 fermentation by reducing in the inhibitory metabolites by cell recycle system and mixed culture. J Biochem Eng 6:207-214. https://doi.org/10.1016/S1369-703X(00) 00089-9

Murooka Y, Piao Y, Kiatpapan P, Yamashita M (2005) Production of tetrapyrrole compounds and vitamin B12 using genetically engineering of Propionibacterium freudenreichii. Lait 85:9-22. https://doi.org/10.1051/lait:2004035

Patrick S, McDowell A (2015) Bergey's manual of systematics of archaea and bacteria. Wiley, New York

Piwowarek K, Lipińska E, Hać-Szymańczuk E (2016) Possibility of using apple pomaces in the process of propionicacetic fermentation. Electron J Biotechnol 23:1-6. https:// doi.org/10.1016/j.ejbt.2016.07.004

Quesada-Chanto A, Afschar S, Wagner F (1994) Microbial production of propionic acid and vitamin B12 using molasses or sugar. Appl Microbiol Biotechnol 41:378-383. https://doi.org/10.1007/BF01982523

Ramsay J, Aly Hassan M, Ramsay B (1998) Biological conversion of hemicellulose to propionic acid. Enzym Microbiol Technol 22:292-295. https://doi.org/10.1016/ S0141-0229(97)00196-8

Roman RV, Iluc E, Mustea A, Neacsu A, Asandului V (2001) Optimisation of medium components in vitamin B12 biosynthesis. Romanian Biotechnol Lett 6:343-350

Scholz CFP, Kilian M (2016) The natural history of cutaneous propionibacteria, and reclassification of selected species within the genus Propionibacterium to the proposed novel genera Acidipropionibacterium gen. nov., Cutibacterium gen. nov. and Pseudopropionibacterium gen. nov. Int J Syst Evol Microbiol 66:4422-4432. https://doi.org/10. 1099/ijsem.0.001367

Suomalainen H, Mäyrä-Makinen M (1999) Propionic acid bacteria as protective cultures in fermented milks and breads. Lait 79:165-174

Suwannakham S, Yang S (2005) Enhanced propionic acid fermentation by Propionibacterium acidipropionici mutant obtained by adaptation in a fibrous-bed bioreactor. Biotechnol Bioeng 91:325-337. https://doi.org/10.1002/ bit. 20473

Teng Y, Xu Y (2008) Culture conditions improvement for whole-cell lipase production in submerged fermentation by 
Rhizopus chinensis using statistical method. Bioresour Technol 99(9):3900-3907. https://doi.org/10.1016/j. biortech.2007.07.057

Thirupathaiah Y, Swarupa Rani C, Sudhakara Reddy M (2012) Effect of chemical and microbial vitamin $\mathrm{B}_{12}$ analogues on production of vitamin $\mathrm{B}_{12}$. World J Microbiol Biotechnol 28:2267-2271. https://doi.org/10.1007/s11274-012-10118

Wang Z, Yang ST (2013) Propionic acid production in glycerol/ glucose co-fermentation by Propionibacterium freudenreichii subsp. shermanii. Bioresour Technol 137:116-123. https://doi.org/10.1016/j.biortech.2013.03.012

Wang P, Wang Y, Liu Y, Shi H, Su Z (2012) Novel in situ product removal technique for simultaneous production of propionic acid and vitamin B12 by expanded bed adsorption bioreactor. Bioresour Technol 104:652-659. https:// doi.org/10.1016/j.biortech.2011.10.047

Wang P, Jiao Y, Liu S (2014) Novel fermentation process strengthening strategy for production of propionic acid and vitamin B12 by Propionibacterium freudenreichii. J Ind Microbiol Biotechnol 12:1811-1815. https://doi.org/10. 1007/s10295-014-1513-5

Wang P, Zhang Z, Jiao Y, Liu S, Wang Y (2015) Improved propionic acid and 5,6-dimethylbenzimidazole control strategy for vitamin B12 fermentation by Propionibacterium freudenreichii. J Biotechnol 193:123-129. https:// doi.org/10.1016/j.jbiotec.2014.11.019

Yazdani SS, Gonzales R (2007) Anaerobic fermentation of glycerol: a path to economic viability for the biofuels industry. Curr Opin Biotechnol 18:213-219. https://doi. org/10.1016/j.copbio.2007.05.002

Yu Y, Zhu X, Shen Y (2015) Enhancing the vitamin B12 production and growth of Propionibacterium freudenreichii in tofu wastewater via a light-induced vitamin B12 riboswitch. Appl Microbiol Biot 99:10481-10488. https://doi. org/10.1007/s00253-015-6958-6

Zhu Y, Li J, Tan M, Liu L, Jiang L, Sun J, Lee P, Du G, Chen J (2010) Optimalization and scale-up of propionic acid production by propionic acid-tolerant Propionibacterium acidipropionici with glycerol as the carbon source. Bioresour Technol 101:8902-8906. https://doi.org/10. 1016/j.biortech.2010.06.070

Zhu L, Wei P, Cai J, Zhu X, Wang Z, Huang L, Xu Z (2012) Improving the productivity of propionic acid with FBBimmobilized cells of an adapted acid-tolerant Propionibacterium acidipropionici. Bioresour Technol 112:248-253. https://doi.org/10.1016/j.biortech.2012.01. 055 